\title{
On the naming of color words and color patches
}

\author{
LAUREN SUE SEIFERT and NEAL F. JOHNSON \\ Ohio State University, Columbus, Ohio
}

\begin{abstract}
Subjects can name color words faster than they can name colcr patches. To account for that effect, a generic model of naming is described which assumes that words access the mental lexicon directly, whereas color patches do so only indirectly via an initial imaginal or semantic representation. However, Lund (1927) reported that the naming advantage for words disappeared when all the items to be named on a page were the same (i.e., they were blocked). In the present study, three experiments are reported that were designed to provide a clearer empirical definition of Lund's blocking effect and to ascertain the extent to which it requires a modification of the generic model. The blocked lists had 50 items arranged into 10 blocks, with each block homogeneous with respect to color. The block lengths were either all a predictable length of 5 items or they varied randomly from 1 to 9 items. The data indicated the following: (1) The blocking effect occurred even when the task required a full identification of each item, and (2) the blocking effect was confined to within-block transitions. Blocking seemed to eliminate the word advantage by allowing the subject to re-use the lexical entry used for the immediately prior item, which is consistent with the generic model.
\end{abstract}

Since Cattell (1886) first noted that the processing of color information takes more time than does the processing of words, there have been literally hundreds of studies devoted to some aspect of this effect (see Glaser, 1992, for a review). Over the past several decades, these explorations have tended to occur primarily in the more complex context of a Stroop (1935b) interference task (see MacLeod, 1991, for a review), but it is also the case that the basic phenomenon demonstrated by Cattell is still lacking a broadly accepted explanation.

One of the early explanations for the advantage of words over color patches in a naming task was framed simply in terms of the strength of the stimulus-response association on the basis of the frequency of the pairing (i.e., how often red, as a visual stimulus, had preceded the naming response "red," as compared with how often the color patch had preceded that naming response). However, although the issue is complicated (Lund, 1927; Stroop, 1935a), and there might be some influence of differential practice with these two types of naming tasks, there also are data that seem to be inconsistent with this very simple associative account (Brown, 1915; Ligon, 1932).

\section{A Generic Model of Naming}

An alternative account that can handle both the naming data and those from the Stroop (1935b) paradigm is

The research reported herein was based on work supported by a National Science Foundation Fellowship to the first author. Any opinions, findings, or recommendations in this article are those of the authors and do not necessarily reflect the views of the National Science Foundation. Correspondence should be sent to Neal F. Johnson, Department of Psychology, Townshend Hall, Ohio State University, Columbus, OH 43210.

-Accepted by previous editor, Margaret Jean Intons-Peterson based on the assumption that visual displays of words directly access the mental lexicon, whereas nonorthographic visual displays (e.g., color patches and objects or pictures of objects) directly access nonlexical imaginal representations. Furthermore, it would be assumed that access to a common amodal semantic memory would follow one of these two types of initial cognitive encoding (i.e., lexical or imaginal) as a subsequent encoding event.

Unfortunately, with regard to this latter point, there is a complicating factor in that there does appear to be a certain intimacy between a nonlexical imaginal encoding and its meaning, but that does not hold for lexical representations and their meaning (e.g., Smith \& Magee, 1980). That is, semantic elaboration benefits the encoding of words but not pictures. This differential intimacy is clearly a complex issue, and it may not reflect any type of privileged relationship (see, e.g., Haase \& Theios, 1992; Snodgrass \& McCullough, 1986; Theios \& Amrhein, 1989). On the other hand, it does seem to be real (Glaser, 1992), and it could be handled by assuming either that the imaginal encoding includes meaning or that it automatically activates projections to semantic memory. That is, if semantic access is required, words and pictures may be equally effective as stimuli, but, for lexical entries, such semantic access may be optional whereas it is not optional for imaginal representations.

If the perceiver's task were to name the display, the needed information would be the lexical representation. The fact that words have an immediate access to the lexicon, whereas nonword stimuli gain lexical access only via a detour through their imaginal representation, would explain why words are named faster. In addition, when there is inconsistent word and nonword information in a dis- 
play, as in a Stroop (1935b) task, there would be no active and competing lexical representation of the nonword information when the word was being named. However, by the time there was an active lexical representation of the nonword information, there would also be a competing lexical representation of the word, and that competition would result in interference.

The foregoing view is generic in the sense that it is not new, and its essential components and structure have been the core of many models in the past (see, e.g., Glaser \& Glaser, 1989; Nelson, Reed, \& McEvoy, 1977; Potter \& Faulconer, 1975; Smith \& Magee, 1980; Snodgrass, 1984; Theios \& Amrhein, 1989). In addition, the model can be detailed by noting that a logical analysis of the task, as well as a substantial body of empirical work on general models of visual information processing, require that it include at least five levels of processing and their attendant forms of representing information. These levels conform roughly to those proposed by Huttenlocher and Kubicek (1983; see also LaHeij, 1988, and Lupker \& Katz, 1981).

The first level is a sensory encoding of the display, and it would involve a relatively uninterpreted precognitive representation of the stimulus input, which can be identified with the work on iconic memory. Specifically, it is assumed that the information would be encoded into physically defined units (e.g., single printed letters) but not cognitively defined units (e.g., words), and the representation would be in the form of physical attributes (e.g. . colors, shapes, etc.) but not cognitive attributes (e.g., Is an item a letter as opposed to being a digit?; see Johnson, 1977, pp. 95-103; Johnson, 1981, pp. 38-41; and Johnson, 1991, pp. 87-91, for brief reviews of the relevant literature). In addition, it is assumed that the rate at which this level of encoding occurs does not vary as a function of whether the display is a picture or a word (see Glaser, 1992, for a brief review).

In the event the sensory representation provides adequate information for the task, subjects should respond faster and more efficiently than if the task required some form of higher level encoding. For example, Lund (1927) had subjects find and point to all instances of a particular color patch or a particular word on a sheet of such items. Because subjects seem able to detect and compare simultaneously available color patches on the basis of a physical (Level 1) comparison (Clark, 1969; Goolkasian, 1981), the sensory representation would be adequate for detecting the color patches. However, for words, subjects do not seem to have the information needed to make such comparisons more than a few spaces from their point of fixation (Rayner, 1975), and, as a result, they would require a subsequent lexical encoding before the perceiver could know whether the item matched the target.

In accordance with that expectation, Lund (1927) found that subjects were much faster at detecting instances of a particular color on pages of color patches than they were at detecting instances of a particular word on pages of color words. Similarly, Clark (1969) found that subjects were very efficient at selectively disregarding irrelevant colors in an iconic memory task (e.g., red dots in the context of detecting blue dots), whereas Sperling (1960) found that when the two types of items represented a cognitive distinction (digits vs. consonants), the subjects were not able to disregard the irrelevant items.

The second level of processing and representation would involve encoding the sensory representation into an initial conceptual form that is compatible with the physical form of the stimulus and that could be used as the basis for identification. A word would require a lexical encoding, whereas a color patch, an object, or the picture of an object would require an imaginal encoding, and identification would occur when this level of encoding became active. If the task demanded the use of this form of encoding (e.g., a simple identification task), perceivers could respond immediately, but if the task required a different form of representation, in the third step of processing the item would be recoded into the needed form. The third step either could involve a semantic encoding of the item, or, in the case of an imaginal representation, could involve the activation of a lexical encoding for the item (although such lexical activation might be semantically mediated).

For example, as noted above, naming requires a lexical representation, and that encoding would be immediately available at the second level of processing if the display was a word, but, for a color patch, there would be a need to recode its Level 2 representation into a lexical encoding. Similarly, if the task required a response based on the item's meaning, it could be done on the basis of Level 3 recoding in order to obtain the needed semantic information.

The implication of these points is that performance in any task requiring only Level 2 encoding will be faster and more efficient than performance in a task requiring Level 3 encoding. This expectation is supported both by the fact that subjects are faster at naming color words than at naming color patches and by the fact that when the need for lexical recoding is eliminated by having subjects use a buttonpress to signal that an item has been identified, the usual latency advantage of responses to words over those to pictures disappears (Fraisse, 1969), as does the Stroop (1935b) effect (McClain, 1983). Smith and Magee (1980) also report data that are consistent with this suggestion regarding Level 2 encoding.

Finally, the fourth and fifth levels of processing involve response selection and response execution. Response selection can be viewed in a variety of ways. For example, one possibility would be to construe it as a momentary priming of a particular response encoding (e.g., a lexical entry), or, alternatively, as the putting of that encoding into a special preexecution buffer. Response execution, on the other hand, would involve activating a selected item so that the information it represents could be recreated. Clearly, these statements represent nothing more than relatively standard and unelaborated characterizations of these two stages. 
In summary, this generic model is simply the set of core assumptions, without the frills, that is common to a wide variety of more detailed models. In addition, it is this set of common assumptions that those models use to account for both the Stroop (1935b) effect (MacLeod, 1991) and the differences in the naming of words and color patches in the absence of interference (Glaser, 1992). Furthermore, the elaboration of those assumptions with the four levels of encoding is really not an elaboration at all, in the sense that it is nothing more than the acknowledgment of several decades of empirical realities that also are either implicit or explicit components of all those models (see, e.g., Huttenlocher \& Kubicek, 1983).

\section{Lund's Blocking Effect}

Although the bulk of the naming data, as well as those obtained with the Stroop (1935b) task, are consistent with this model, there is one interesting empirical effect (Lund, 1927) that is not well understood and that may have implications regarding the foregoing account of naming. Specifically, Lund demonstrated that when subjects were given a sheet of paper containing all the items to be named, and if all the items on the sheet were the same (e.g., all the color patches were red or all the words were the word red), there was no difference in the naming time for colors and words. On the other hand, if the sheet contained the same number of items, but consisting of a random arrangement of different colors or color words, word naming did have a latency advantage. This reduction or disappearance of the naming advantage for words when the displays on a sheet are all the same will be referred to as Lund's blocking effect, and the following experiments were designed to explore this phenomenon. Specifically, the goals were to provide a more detailed empirical definition of this blocking effect and to determine the extent to which it can be explained within the context of the foregoing generic model.

One very obvious and simple explanation for the absence of a word advantage in Lund's (1927) task in which items were blocked (i.e., all the items on the sheet were the same) is that, when the subjects were handed the sheet, they may have just noted that all the items were the same. They then could have provided a lexical encoding for that item, and, when the task began, they could have just repeated that lexical encoding as often as there were items on the page. If subjects did proceed in that manner, although certain automatic encoding events might occur as perceivers move from one item to the next on a display sheet, their performance would not be dependent on the encoding of any specific item information. If that is the explanation, the blocking effect is not inconsistent with the foregoing model, and the problem is that the experimental task is flawed and theoretically uninteresting. The major issue for the following experiments, then, is to determine whether the blocking effect occurs even when the task requires that each item be encoded to the point of identification.

\section{EXPERIMENT 1}

The purpose of Experiment 1 was to assess the extent to which Lund's (1927) blocking effect is attributable to the fact that the subjects could see that all of the items on the blocked sheets were the same and that therefore they needed to encode the target only once. In this experiment, the displays also were blocked, but instead of the items on a whole display sheet being the same, the blocked condition employed display sheets that had 10 blocks of 5 items. That is, there would be a run of five instances of one color patch or color word, followed by a run of five instances of another color patch or color word, and so forth, and there would be 10 such runs on a display sheet organized into five columns with 10 items in each column.

If, in the Lund (1927) experiments, the blocking itself was responsible for the effect, there also should be such an effect under these conditions, even though it might be reduced because of the fact that there is more than one block. On the other hand, the fact that the blocked sheets actually have several blocks per sheet would preclude subjects from just noting that all the items are the same and engaging in one encoding event prior to the onset of the task.

\section{Method}

The design of this experiment involved tasks in which the different items on a display list (color words or color patches) either were randomly arranged or were arranged in blocks of 5 items, with the items in each block homogeneous with respect to color name. The colors used were blue, green, red, orange, and brown; 10-pitch pica type was used for the lists of color words. The displays appeared on legal-size paper $(8.5 \times 14 \mathrm{in}$. $)$, and there were five columns of 10 items each. The color patches were $1 \times 2 \mathrm{~cm}$, and, for both the words and patches, the center-to-center distance between items in a column was $3 \mathrm{~cm}$, with the left edges of the items in adjacent columns $3.75 \mathrm{~cm}$ apart.

There were 10 instances of each color on both the color-word and color-patch sheets, and, for the randomly arranged sheets, the only constraint was that a color could not follow itself. For the blocked sheets, the items were arranged into 10 blocks of 5 items each, with the items within a block homogeneous with respect to color. There were 2 blocks of each color on a sheet, and the order of blocks was random with the exception that the 2 blocks for the same color could not be successive. Finally, for each blocked sheet of color patches and each sheet of randomized individual color patches, there was a corresponding sheet of color words with the same randomization, and there were 10 such pairs of sheets for both the blocked and the randomized conditions (i.e., 40 display sheets in all). In addition, there was one sheet of randomized color patches and one of randomized words that were used for practice.

Procedure. When the subjects arrived to be tested, they were first tested for color blindness with the Ishihara color plates and some sample color patches similar to those used in the experiment. The task was then described to the subjects, and they were given the two practice sheets. The first practice sheet was covered with white paper and was placed in front of the subject. The subjects were told to name each item on the sheet as fast as possible and to point to the item with their finger as they named it. When they reached the bottom of the first column, they were to move over to the bottom of the second column and move up as they named the items; when they reached the top of the second column, they were to move to the top of the third column and go down that 
column, and so forth. Finally, the subjects were told to correct any errors that they made.

After they were given the two practice sheets, one naming color words and the other naming color patches, the subjects were given the eight test sheets, two representing each of the four conditions in the experiments (i.e., random words and patches, and blocked words and patches). The subjects were given one sheet representing each of the four conditions, followed by the second sheet for each of the conditions, and within that constraint the order of the lists was random except for the fact that, across subjects, each condition appeared in each of the eight list positions equally often. The task and instructions were the same for the test sheets as for the practice sheets, and, before a list was presented, the subjects were informed as to whether it contained words or patches, but no comment was ever made with regard to blocking. The experimenter timed the subjects by using a stopwatch, and the two dependent variables were the total time required to name all the items on a sheet and the number of errors made on each sheet.

Subjects. Two subjects were eliminated because they failed the initial screening for color blindness. The remaining 30 subjects were introductory psychology students who participated as part of a course option. All the subjects were native speakers of American English, and they all reported having normal or corrected-to-normal vision.

\section{Results}

An analysis of the error data (Table 1) demonstrated that the subjects committed very few errors. They made more errors on random lists than on blocked lists $[F(1,29)$ $\left.=6.38, M S_{\mathrm{e}}=.89, p<.05\right]$ and more errors on colorpatch lists than on color-word lists $[F(1,29)=15.85$, $\left.M S_{\mathrm{e}}=.74, p<.01\right]$. In addition, there was a significant interaction between blocking and type of stimulus $[F(1,29)$ $\left.=9.50, M S_{\mathrm{e}}=.60, p<.01\right]$, which indicates that blocking reduced errors for the color-patch lists $[F(1,29)=$ $\left.10.39, M S_{\mathrm{e}}=1.10, p<.05\right]$ but not for the color-word lists $\left[F<1.00, M S_{\mathrm{e}}=.40\right]$. In addition, it is interesting to note that, for the blocked lists, $98 \%$ of all errors occurred on the transitions between blocks.

In terms of speed of naming, mean response rates $(\mathrm{Ta}-$ ble 2) were faster for blocked lists than for random lists $\left[F(1,29)=97.60, M S_{\mathrm{e}}=12.00, p<.01\right]$, and they were faster for color-word lists than for color-patch lists

Table 1

Percentage of Errors for Experiment 1

\begin{tabular}{cccc}
\hline & \multicolumn{3}{c}{ Stimulus } \\
\cline { 2 - 4 } List & Word & Color & Means \\
\hline Random & .20 & .95 & .58 \\
Blocked & .20 & .33 & .27 \\
Means & .20 & .64 & .42 \\
\hline
\end{tabular}

Table 2

Response Times (in Seconds) for Experiment 1

\begin{tabular}{cccc}
\hline & \multicolumn{3}{c}{ Stimulus } \\
\cline { 2 - 4 } List & Word & Color & Means \\
\hline Random & 20.65 & 25.74 & 23.19 \\
Blocked & 19.03 & 18.52 & 18.78 \\
Means & 19.84 & 22.13 & 20.99 \\
\hline
\end{tabular}

$\left[F(1,29)=55.61, M S_{\mathrm{e}}=5.67, p<.01\right]$. The critical interaction between blocking and type of stimulus also was significant $\left[F(1,29)=114.66, M S_{\mathrm{e}}=4.11, p<.01\right]$, and pairwise comparisons revealed that although reading had an advantage over color naming on random lists $\left[F(1,29)=121.32, M S_{\mathrm{e}}=6.41, p<.01\right]$, the advantage was reversed on blocked lists $[F(1,29)=2.32$, $\left.M S_{\mathrm{e}}=3.36, p>.05\right]$.

\section{Discussion}

Experiment 1 replicated the well-documented finding that color-word naming was faster than color-patch naming when the order of the presentations of stimuli was random (Brown, 1915; Garrett \& Lemmon, 1924; Hollingworth, 1915; Lund, 1927; Woodworth \& Wells, 1911). Furthermore, this experiment also supported Lund's evidence that color-word naming was not faster than colorpatch naming when the items in the lists were blocked, such that identical items occurred within a block.

In addition, this study also demonstrated that the effect of blocking stimulus lists was not dependent on the same naming response being used for all items on a page. That suggests that Lund's (1927) blocking effect did not stem from subjects simply encoding the first item on the page (for blocked lists) and then just repeating that response as many times as there were items on the page (i.e., simply counting events instead of encoding them). In this experiment, at the very minimum, the subjects were forced to attend to every sixth item on a page in order to encode the first item of each new block, yet the blocking effect was still obtained.

\section{EXPERIMENT 2}

Experiment 1 replicated Lund's (1927) blocking effect in a slightly different task environment, and its results indicate that the effect cannot be attributed to something as simple as subjects just encoding the presented item once per page of displays and then repeating it as often as there are items on the page. However, there are at least three alternative accounts of the blocking effect that are equally simple, and which also would suggest that the implications of the effect for the generic model are limited or nonexistent.

The first account is that it is still possible that, under the blocked condition, subjects may be able to name the items within a block without first encoding them to the point of identification. For example, when subjects see and name an item on a display sheet, they can also see the next item on the page, which would allow for a simultaneous comparison. That very simple physical comparison (Level 1 encoding) would cue them as to whether they should use the same response for that next item, even before they actually produce the name for the first item. In addition, the use of such a physical comparison would allow subjects to make a decision and select a response prior to processing the stimulus event to the point of identification. 
Second, for the blocked sheets, subjects may note very early that every block has five items and then just produce each response five times before engaging in a new encoding event. Again, the blocking would facilitate performance, but it would do so in a task environment that did not require the identification of each stimulus event within a block.

Finally, the third possible account is in terms of interference. For example, it may be that when the sheet contains patches of many different colors, or when there are many different color words on the sheet, the items in the perceivers' parafoveal and peripheral vision provide interference as the perceivers are attempting to name a target item (i.e., a Stroop-like interference effect). However, the fact that words can be semantically processed only a few spaces from the point of fixation (Rayner, 1975), whereas colors can be processed several degrees from the point of fixation (Goolkasian, 1981), suggests that there would be greater interference when the sheet contains color patches than when it contains color words. That differential interference would account for both the word advantage that Lund (1927) obtained and the fact that it disappeared when the items were blocked (i.e., there would be a drop in interference resulting from a reduction in the number of surrounding items that had a different color).

Both the account based on simultaneous physical comparisons and the interference explanation assume that subjects are exposed to more than one stimulus item at a time, as was the case in Experiment 1. That problem was eliminated in the present experiment by employing a screen with a small aperture that covered all but the item currently being named. The subjects moved the screen and named each item as it appeared in the aperture. The time between succeeding stimuli, plus the masking effect of the second of two adjacent stimuli on the first, would preclude a simple physical (Level 1) comparison. For that reason, the comparison would have to be between a memory of the identity of the prior stimulus and a comparable encoding of the current stimulus. In addition, there would be no other stimuli in view to cause interference.

If the blocking effect occurs because subjects encode, to the point of identification, only the first item in each block and then use that encoding five times (i.e., count detected events without identifying them), the blocking effect would be eliminated if subjects had no way of knowing when a block ended. Experiment 2 also included a set of conditions that explored that possibility. It compared a group that had predictable blocks of a fixed length of 5 items, as in Experiment 1, with a group that had unpredictable blocks that averaged 5 items in length, but whose lengths varied randomly from 1 to 9 . The screen with the small aperture was used for both conditions, but only for the condition with unpredictable block lengths would the subjects have no way of knowing in advance when one block ends and the next block begins.

On the other hand, if subjects always identify each display before responding, the predictability of block lengths would be irrelevant. Within that context, an alternative possibility, and one that does have implications with regard to the generic model, is that subjects actually do provide an initial conceptual encoding for each item as it appears (i.e., a Level 2 encoding), but when using that encoding as a basis for response selection, they first make an initial determination as to whether the lexical entry used for the immediately preceding item is still appropriate. If it is appropriate, (i.e., the two identity encodings match), that already available lexical encoding is selected and executed (see Rabbitt \& Rodgers, 1977, for a similar use of this idea to account for repetition effects on latency).

However, if that lexical entry is not appropriate, and the initial conceptual encoding also is not the one needed for the task (e.g., the task is naming, and the display is a color patch), Level 3 recoding would be needed to obtain the appropriate representation. When subjects name color patches, this level of encoding would occur at each block-to-block transition, but it would not occur on transitions between items within blocks. In addition, although it would occur only $20 \%$ of the time for blocked lists, it would have to occur for every transition on the random lists.

The issue, then, is the extent to which Lund's (1927) blocking effect is dependent on subjects' ability to name the items within a block of displays without first identifying them, with the alternative being that the effect occurs despite the need for such conceptual encoding. The tasks employed in this experiment forced the subjects to provide a conceptual encoding for each item by eliminating all sources of information regarding the nature of a display prior to its appearance, and the empirical issue was whether the blocking effect would occur even under these circumstances. If it is obtained, our understanding of the blocking effect will have a direct bearing on how best to construe the difference, if any, between the naming of print objects and nonprint objects.

\section{Method}

The screen was made with a $43 \times 71 \mathrm{~cm}$ piece of lightweight (but opaque) white cloth glued to the bottom of the blade of a spatula. The aperture $(2.5 \times 3 \mathrm{~cm})$ was cut through the center of the blade and cloth, and the subjects held the handle of the spatula to move the screen. The screen moved very easily and smoothly over the display sheets, and the subjects simply moved the aperture to the next item on a sheet before naming it, instead of moving their finger as in Experiment 1 . In all other respects, the procedures for the two experiments were exactly the same.

Experiment 2 involved two replications of Experiment 1, except that the screen was always used and, for one of the replications, the block lengths varied randomly from 1 to 9 items, instead of being a constant 5 . Random-length (or unpredictable) blocks versus fixed-length (or predictable) blocks was a between-subject factor, and the subjects were assigned to those two conditions in random order as they appeared for the experiment. There were 30 subjects in each condition, and they were drawn from the same population that was used for the other experiments.

For the predictable condition, the sheets were the same as in Experiment 1 . However, for the unpredictable condition, although the sheets of random items were the same as in Experiment 1, the blocked lists had one block each of lengths 1 through 9, except that 
there were two blocks of length 5. On a specific presentation sheet, each color appeared in two blocks, but there was no attempt to insure that each color occurred equally often on a sheet. For example, brown might appear in blocks of one and three, whereas red would be in blocks of nine and eight. However, across the 10 display sheets used in the experiment for the unpredictable blocked conditions, each color appeared in each block length equally often, and, for each sheet of color patches, there was a corresponding sheet of color words in which the items appeared in the same order. Finally, on any particular sheet, the order of block lengths and colors was random, within the constraints that there could not be two consecutive blocks of the same color and, across sheets, every color had to appear in every block length equally often. In all other respects, however, the unpredictable condition was an exact replication of the predictable condition.

\section{Results}

The error data are given in Table 3 and are similar to those for Experiment 1. Overall, there was no main effect of predictability $\left[F<1.00, M S_{\mathrm{e}}=3.03\right]$, but the subjects made more errors on the color patches than on the words $\left[F(1,58)=37.45, M S_{\mathrm{e}}=3.65, p<.001\right]$ and more errors on the random lists than on the blocked lists $\left[F(1,58)=19.86, M S_{\mathrm{e}}=1.20, p<.001\right]$. In addition, the interaction between blocking and type of item also was significant $\left[F(1,58)=46.73, M S_{\mathrm{e}}=2.00, p<.001\right]$, but the other interactions all yielded $F$ s of less than 1.00 .

For the predictable blocking condition, there were fewer errors on blocked items than on random items $[F(1,29)=$ $\left.6.39, M S_{\mathrm{e}}=2.84, p<.01\right]$ and fewer errors on color words than on color patches $\left[F(1,29)=14.28, M S_{\mathrm{e}}=\right.$ $4.62, p<.01]$. In addition, there was a significant interaction between blocking and type of item $[F(1,29)=$ $\left.19.91, M S_{\mathrm{e}}=2.18, p<.01\right]$, with blocking increasing errors for the words $\left[F(1,29)=5.48, M S_{\mathrm{e}}=.49, p<\right.$ $.05]$, while reducing them for the patches $[F(1,29)=$ $\left.13.00, M S_{\mathrm{e}}=4.52, p<.001\right]$.

For the unpredictable blocking condition, the subjects also made more errors on random items than on blocked items $\left[F(1,29)=14.89, M S_{\mathrm{e}}=2.27, p<.01\right]$ and more errors on color patches than on color words $[F(1,29)=$

Table 3

Percentage of Errors for Experiment 2

\begin{tabular}{lrrr} 
& \multicolumn{3}{c}{ Stimulus } \\
\cline { 2 - 3 } List & Word & Color & Means \\
\hline Predictable & & & \\
Random & .10 & 2.00 & 1.05 \\
Blocked & .40 & .60 & .50 \\
Means & .25 & 1.30 & .78 \\
Unpredictable & & & \\
$\quad$ Random & .13 & 2.13 & 1.13 \\
$\quad$ Blocked & .30 & .47 & .38 \\
Means & .22 & 1.30 & .76 \\
Both Conditions & & & \\
$\quad$ Random & .12 & 2.07 & 1.09 \\
$\quad$ Blocked & .35 & .53 & .44 \\
Means & .23 & 1.30 & .77 \\
\hline
\end{tabular}

Table 4

Response Times (in Seconds) for Experiment 2

\begin{tabular}{llll} 
List & Word & Color & Means \\
\hline Predictable & & & \\
$\quad$ Random & 31.58 & 38.44 & 35.01 \\
$\quad$ Blocked & 29.87 & 29.65 & 29.76 \\
Means & 30.73 & 34.05 & 32.39 \\
Unpredictable & & & \\
$\quad$ Random & 31.16 & 36.93 & 34.04 \\
$\quad$ Blocked & 31.28 & 31.66 & 31.47 \\
Means & 31.22 & 34.29 & 32.76 \\
Both Conditions & & & \\
$\quad$ Random & 31.37 & 37.69 & 34.53 \\
$\quad$ Blocked & 30.58 & 30.66 & 30.62 \\
Means & 30.97 & 34.17 & 32.57 \\
\hline
\end{tabular}

$\left.26.49, M S_{\mathrm{e}}=2.66, p<.01\right]$. In addition, there was a significant interaction between blocking and type of item $\left[F(1,29)=27.54, M S_{\mathrm{e}}=1.83, p<.01\right]$, with the blocking effect significant for the patches $[F(1,29)=$ 22.66, $\left.M S_{\mathrm{e}}=3.68, p<.01\right]$ but not for the words $\left[F(1,29)=1.99, M S_{\mathrm{e}}=.42, p>.05\right]$. Finally, almost all of the errors on blocked lists occurred at transitions between blocks of items ( $98 \%$ for the unpredictable condition, and $97 \%$ for the predictable condition), and color words and color patches were not reliably different in this regard for either of the two main conditions.

The data for speed of naming are presented in Table 4 . There was no main effect for predictability $[F<1.00$, $\left.M S_{\mathrm{e}}=146.58\right]$, but the subjects were faster on blocked lists than on random lists $\left[F(1,58)=234.14, M S_{\mathrm{e}}=\right.$ $7.85, p<.01]$, and they were faster on color words than on color patches $\left[F(1,58)=106.29, M S_{\mathrm{e}}=11.54, p<\right.$ $.01]$. In addition, there were reliable interactions between blocking and type of item $\left[F(1,58)=283.97, M S_{\mathrm{e}}=\right.$ $4.10, p<.01]$, as well as between predictability and blocking $\left[F(1,58)=27.44, M S_{\mathrm{e}}=7.85, p<.01\right]$, and the three-way interaction also was significant $[F(1,58)=$ $\left.5.25, M S_{\mathrm{e}}=4.10, p<.05\right]$.

In general, there was a larger effect of blocking on the color patches (i.e., Lund's, 1927, blocking effect), and the reliable three-way interaction suggests that the tendency for blocking to reduce or eliminate the color-word advantage was somewhat greater for the predictable condition. However, that interpretation is clouded by what appears to be a problem with heterogeneity of variance. For example, as will be noted below, although in absolute terms the interaction between blocking and item type is larger for the predictable condition, the $F$-value for that interaction is actually substantially smaller than for the comparable interaction for the unpredictable condition (138.09 vs. 157.42 ).

The results from separate analyses of the between-group conditions were similar to the results of the overall anal- 
ysis. In the predictable blocking condition, the subjects were faster on blocked sheets than on random sheets $\left[F(1,29)=199.53, M S_{\mathrm{e}}=8.29, p<.01\right]$, they were faster on color words than on color patches $[F(1,29)=$ $\left.40.61, M S_{\mathrm{e}}=16.30, p<.01\right]$, and the interaction between these two factors also was significant $[F(1,29)=$ $\left.138.09, M S_{\mathrm{e}}=5.44 . p<.01\right]$. Similarly, for the unpredictable condition, the subjects were faster on blocked than on random lists $\left[F(1,29)=53.71, M S_{\mathrm{e}}=7.40, p<\right.$ $.01]$, they were faster for color words than for color patches $\left[F(1,29)=83.57, M S_{\mathrm{e}}=6.78, p<.01\right]$, and, again, the interaction was significant $[F(1,29)=157.42$, $\left.M S_{\mathrm{e}}=2.27, p<.01\right]$.

Pairwise comparisons revealed that, for the predictable blocking condition, the subjects were significantly faster on blocked color patches than on random color patches $\left[F(1,29)=275.89, M S_{\mathrm{e}}=8.40, p<.01\right]$ and on blocked color words than on random color words $[F(1,29)=$ $\left.16.48, M S_{\mathrm{e}}=5.33, p<.01\right]$. The two random conditions did differ reliably $\left[F(1,29)=89.10, M S_{\mathrm{e}}=15.85\right.$, $p<.01]$, but the two blocking conditions were not reliably different $\left(F<1.00, M S_{\mathrm{e}}=5.89\right)$. Pairwise comparisons for the unpredictable condition revealed that the subjects were significantly faster on blocked color patches than on random color patches $\left[F(1,29)=109.01, M S_{\mathrm{e}}=\right.$ $7.63, p<.01]$, but the naming times for blocked color words and random color words were not reliably different $\left[F<1.00, M S_{\mathrm{e}}=2.53\right]$. For the random condition, the subjects were slower on the color patches $[F(1,29)=$ $\left.140.98, M S_{\mathrm{e}}=7.08, p<.01\right]$, but the difference between the two blocking conditions was not significant $\left[F(1,29)=1.75, M S_{\mathrm{e}}=2.47, p>.05\right]$.

Finally, it is important to note that the use of the screen did have a very marked effect on the subjects' performance. In comparison with Experiment 1, there was an increase of about $50 \%$ in both the error rate and the mean response latency. That was true for both the word lists and the lists of color patches, which suggests that having prior visual information regarding an upcoming display is an important determiner of a subject's performance.

\section{Discussion}

The results of this experiment indicate very clearly that prior knowledge of when a block of same-named items will end is not a precondition for Lund's (1927) blocking effect. In both major conditions, there was a marked advantage for naming color words over naming color patches when the items on the sheets were random and unblocked. However, the difference in naming time disappeared when the items were blocked, even when the block lengths varied randomly and the screen precluded the subjects from seeing an upcoming item until it was time to respond. In general, then, Lund's blocking effect seems to have occurred even when the task required the encoding of each item to the point of identification, which suggests that the facilitating effect of blocking is occurring at some point subsequent to that initial conceptual encoding.

\section{EXPERIMENT 3}

The current data indicate that the initial encoding events up through identification are not a factor in Lund's (1927) blocking effect, whereas the Fraisse (1969) data indicate that the word advantage for random lists occurs only when the task requires lexical access. That combination of facts suggests that the blocking effect occurs because blocking allows the perceiver to use the initial encoding to bypass the activation of a lexical entry. However, because a lexical encoding is needed (i.e., the task involves naming), the implication is that lexical activation is bypassed because the needed encoding is already active and available.

Specifically, in terms of the generic model, a reasonable account of the facilitation of color-patch naming from blocking is that the lexical entry for an item is kept active (i.e., it remains "selected") until after the next item is presented. If the imaginal representation of the new display matches the perceiver's memory of the immediately preceding display, that lexical encoding is simply reencoded into its motor routine and executed. Another possibility is that the motor routine itself somehow remains in an active or primed state, and the match between the imaginal representation and the memory just retriggers that execution. In fact, it is possible that one or the other of these strategies is the general case, such that an encoding of the immediately preceding item is always available for use, regardless of whether the items are blocked or random, or whether they are words or patches, and it is only in the blocked situation that the availability becomes evident.

For both of the foregoing options, the critical assumption is that lexical activation would be necessary only on trials that are transitions from one block to the next, for which a new lexical encoding would be needed. Only at those points should there be any difference in the way words and color patches are handled. For random lists, every transition would be of this type, whereas, for blocked lists, only the between-block transitions would be. Within blocks, on the other hand, the initial encoding (imaginal or lexical) would immediately lead to the motor encoding or reexecution of the correct response, regardless of the type of display, and response times should be the same for the naming of color words and color patches.

Along with the usual random-list condition, the present experiment employed the blocked lists from Experiment 2, in which the block lengths varied unpredictably. However, instead of using the screen and sheets of paper on which the items appeared, the displays were presented as single items in the center of a computer screen, and the subjects responded by naming the display (consisting of either a color word or a small colored square). A voice key tripped a timing device, and a separate latency was recorded for each stimulus. In that way, latencies for between-block and within-block transitions could be kept separate. 
In addition, immediately before each display, a small black square appeared in the center of the screen as a fixation point. Half of the subjects just looked at the black square as a fixation point and named the subsequent display, whereas the other half of the subjects said "square" when the small black square appeared and then also named the subsequent display. The rationale for this factor was that although it is quite likely that subjects could have more than one lexical entry primed and active at any point in time, it is unlikely that two motor routines could be simultaneously active. If that is the case, that is, if the carryover from one display to the next is an active motor routine, rather than a primed lexical entry, the saying of "square" between displays should eliminate the carryover, and the blocking effect should disappear.

Finally, it has been argued that identity (Level 2) encodings are used when subjects determine whether a new stimulus is the same as the immediately preceding stimulus. The reason it is assumed that a sensory (Level 1) encoding cannot be used is that the time between succeeding stimulus events (about $750 \mathrm{msec}$ ), plus the masking effect of the second stimulus, would preclude there being any lingering sensory representation of Stimulus $N-1$ when Stimulus $N$ appeared. For that reason, a decision could not be made on the basis of a simple sensory-level comparison, and a more durable memorial encoding of the prior stimulus would be needed.

In the present experiment, the possibility of a lingering sensory representation of the prior stimulus was reduced even further by increasing the duration of the interstimulus interval to several seconds, which, according to the Posner, Boies, Eichelman, and Taylor (1969) data, should preclude the subjects from making a physical comparison. In addition, the black square used as a fixation point intervened between the two stimulus events, which would effectively mask the first stimulus, even if the interval were not sufficiently long.

\section{Method}

Apparatus and Materials. The colors and color patches were red, blue, yellow, purple, and green, and they appeared in the center of a VGA computer screen with a white background. The words were black and typed in lowercase in a standard typeface; the color patches were $1 \times .5 \mathrm{in}$. Each display was preceded by a black square $(1 \times 1 \mathrm{~cm})$ as a fixation point, which, for the subjects who did not say "square," remained in view for about $750 \mathrm{msec}$. For the subjects who did say "square," the black square went off about $500 \mathrm{msec}$ after their response. In each case, when the square went off the screen, it was immediately replaced by the color word or color patch, which remained in view until after the subject responded.

With the exceptions that a computer was used, that the unit of analysis was the response to an individual display (rather than naming times for a whole sheet), that the foregoing display characteristics were employed, that each display was preceded by a predisplay fixation point, and that the subjects did or did not say "square" when the fixation display appeared, this experiment was exactly the same as the condition in Experiment 2 whose blocked displays had blocks of random lengths. Instead of 10 sheets of 50 items, there were 10 sets of 50 trials. There were 2 sets of trials in which color words appeared randomly and 2 sets in which color patches appeared ran- domly, and, as before, the only constraint was that, within a set of trials, an item could not follow itself. Two additional sets of trials were constructed in the same manner and were used for practice. One set of practice trials had words; the other set had patches.

In addition, there were 2 sets of 50 trials of color words and 2 sets of 50 trials of color patches in which the items appeared in blocks, within which the items were homogeneous with regard to color name. Within a set of 50 blocked trials, there was one block each of lengths 1 through 9, except that there were two blocks of 5 items. The assignment of colors to blocks, the randomization of block lengths, and the order in which the lists or trial sets were presented were the same as in Experiment 2, except that instead of having only 1 set of 10 randomized sheets used for all subjects, a separate set of 10 randomized trial sets was created for each subject.

Procedure. The subjects were first given the two sets of practice trials, with half of them getting patches before words and the other half getting words before patches. That was followed by the eight sets of 50 trials that were the test items. Before a set of trials was presented, the subjects were informed as to whether the displays would be words or patches. Half of the subjects were told that, for all of their trial sets, they were to say the word "square" when they saw the black square as a prefixation display, and the other subjects were simply told to look at the square. They were all told that shortly thereafter the display (word or patch) would appear and that they were to name it as quickly as possible, speaking into a microphone that they held in their hand. The experimenter determined the flow of the experiment by pressing a key to initiate each test trial (i.e., the black square followed by a display). The subjects also were told not to correct any naming errors (corrections sometimes disrupted the timing of the next trial).

Subjects. The subjects were 32 students from the same population used for the prior experiments. Sixteen subjects were randomly assigned to each of the between-subject conditions (saying or not saying "square"), and they were pretested with the Ishihara plates to be certain that they were not color blind

\section{Results}

The overall error data are presented in Table 5, and a breakdown of the data for the blocked condition in terms of between-block versus within-block transitions is given in Table 6. With regard to the overall analysis, the error rate across all conditions was $5.53 \%$, but none of the spe-

Table 5

Percentage of Errors for Experiment 3

\begin{tabular}{|c|c|c|c|}
\hline \multirow[b]{2}{*}{ Display Condition } & \multicolumn{3}{|c|}{ Stimulus } \\
\hline & Word & Color & Means \\
\hline $\begin{array}{l}\text { Not saying "square" } \\
\text { Random } \\
\text { Blocked }\end{array}$ & $\begin{array}{l}3.88 \\
5.69\end{array}$ & $\begin{array}{l}5.50 \\
3.81\end{array}$ & $\begin{array}{l}4.69 \\
4.75\end{array}$ \\
\hline Means & 4.78 & 4.66 & 4.72 \\
\hline $\begin{array}{l}\text { Saying "square" } \\
\text { Random } \\
\text { Blocked }\end{array}$ & $\begin{array}{l}4.81 \\
8.00\end{array}$ & $\begin{array}{l}4.81 \\
7.75\end{array}$ & $\begin{array}{l}4.81 \\
7.88\end{array}$ \\
\hline Means & 6.41 & 6.28 & 6.34 \\
\hline $\begin{array}{l}\text { Both conditions } \\
\text { Random } \\
\text { Blocked }\end{array}$ & $\begin{array}{l}4.34 \\
6.84\end{array}$ & $\begin{array}{l}5.16 \\
5.78\end{array}$ & $\begin{array}{l}4.75 \\
6.31\end{array}$ \\
\hline Means & 5.59 & 5.47 & 5.53 \\
\hline
\end{tabular}


cific effects were reliable, with the largest effect being whether the displays were random or blocked $[F(1,30)=$ $\left.3.05, M S_{\mathrm{e}}=25.63, p>.05\right]$. The separate analysis of the blocked condition indicated that the only effect to be reliable was the transition-type $\times$ display-type interaction $\left[F(1,30)=5.15, M S_{\mathrm{e}}=18.01, p<.05\right]$, indicating a smaller difference between words and patches within blocks than between blocks, although the between-block difference itself was not reliable $\left[F(1,30)=2.06, M S_{\mathrm{e}}=\right.$ $64.24, p>.05]$.

The overall latency data are presented in Table 7 . Unexpectedly, the subjects were significantly faster at naming the target display if they had said "square" when the predisplay fixation square appeared $[F(1,30)=7.59$, $\left.M S_{\mathrm{e}}=12,138, p<.05\right]$, but that main effect did not interact with either display type (word vs. patch) $(F<$ $1.00, M S_{\mathrm{e}}=2,903$ ) or blocking condition (blocked vs. random presentation; $\left.F<1.00, M S_{\mathrm{e}}=1,024\right)$, and the three-way interaction also was not significant $[F(1,30)=$ $\left.1.58, M S_{\mathrm{e}}=1,579, p>.05\right]$.

The subjects named words faster than they named colors $\left[F(1,30)=46.03, M S_{\mathrm{e}}=2,903, p<.01\right]$, and they named items in the blocked condition more rapidly than they named items in the random condition $[F(1,30)=$ 120.36, $\left.M S_{\mathrm{e}}=1,024, p<.01\right]$. Finally, the critical display-type $\times$ blocking-condition interaction also was reliable $\left[F(1,30)=45.30, M S_{\mathrm{e}}=1,579, p<.01\right]$, indicating that once again, the latency advantage for naming color words over color patches was significantly reduced when the displays were blocked.

Specific comparisons indicate that, for the color patches, the subjects were faster when the displays were blocked $\left[F(1,30)=91.67, M S_{\mathrm{e}}=2,087, p<.01\right]$, which was also true for the words $\left[F(1,30)=6.77, M S_{\mathrm{e}}=682\right.$, $p>.05]$. In addition, when the displays were blocked, the subjects were faster at naming words than at naming color patches $\left[F(1,30)=7.03, M S_{\mathrm{e}}=685, p<.05\right]$, which was true for the random condition as well $\left[F(1,30)=52.77, M S_{\mathrm{e}}=3,797, p<.01\right]$. In general,

Table 6

Percentage of Errors for the Blocked Lists of Experiment 3

\begin{tabular}{lccc}
\hline & \multicolumn{3}{c}{ Stimulus } \\
\cline { 3 - 4 } Display Condition & Word & Color & Means \\
\hline Not saying "square" & & & \\
Between blocks & 7.19 & 5.63 & 6.41 \\
Within blocks & 6.25 & 5.44 & 5.84 \\
Means & 6.71 & 5.53 & 6.13 \\
Saying "square" & & & \\
Between blocks & 9.38 & 5.19 & 7.28 \\
Within blocks & 8.00 & 9.88 & 8.94 \\
Means & 8.68 & 7.53 & 8.11 \\
Both conditions & & & \\
Between blocks & 8.28 & 5.41 & 6.85 \\
Within blocks & 7.13 & 7.66 & 7.40 \\
Means & 7.71 & 6.54 & 7.12 \\
\hline
\end{tabular}

Table 7

Response Times in (Milliseconds) for Individual Items for Experiment 3

\begin{tabular}{llll}
\hline & \multicolumn{3}{c}{ Stimulus } \\
\cline { 4 - 4 } Display Condition & Word & Color & Means \\
\cline { 4 - 4 } $\begin{array}{l}\text { Not saying "square" } \\
\text { Random }\end{array}$ & & & \\
$\quad$ Blocked & 537 & 657 & 597 \\
Means & 529 & 536 & 533 \\
Saying "square" & 533 & 597 & 565 \\
$\quad$ Random & & & \\
$\quad$ Blocked & 489 & 593 & 541 \\
Means & 468 & 495 & 481 \\
Both conditions & 478 & 544 & 511 \\
Random & & & \\
$\quad$ Blocked & 513 & 625 & 569 \\
Means & 498 & 516 & 507 \\
\hline
\end{tabular}

then, blocking did yield the usual facilitation for naming color patches as well as for naming color words, but it did not completely eliminate the usual latency advantage of naming color words over naming color patches. Overall, the pattern of data is similar to that obtained for the same conditions in Experiment 2, except that, in this experiment, blocking did facilitate the naming of color words and the word advantage did not completely disappear with blocked displays.

The second set of analyses of the latency data involved a comparison of the within-block and between-block transitions for the blocked conditions. Those data are presented in Table 8. Again, the subjects who said "square" were faster than those who did not say "square" $[F(1,30)$ $=5.95, M S_{\mathrm{e}}=12,536, p<.05$ ], but that effect did not interact with either type-of-display $\left(F<1.00, M S_{\mathrm{e}}=\right.$ $1,905)$ or with type-of-transition $\left[F(1,30)=1.22, M S_{\mathrm{e}}=\right.$ $1,595, p>.05]$, and the three-way interaction also was not reliable $\left(F<1.00, M S_{\mathrm{e}}=837\right)$.

The subjects named words faster than they named patches $\left[F(1,30)=22.48, M S_{\mathrm{e}}=1,905, p<.01\right]$, and they were faster on within-block transitions than on between-block transitions $\left[F(1,30)=149.91, M S_{\mathrm{e}}=\right.$ $1,595, p<.01]$. In addition, the type-of-display $\times$ typeof-transition interaction also was significant $[F(1,30)=$ 40.59, $M S_{e}=836, p<.05$ ], indicating that although there was little difference between words and patches on within-block transitions $\left(F<1.00, M S_{\mathrm{e}}=685\right)$, the usual word advantage was apparent on the between-block transitions $\left[F(1,30)=37.22, M S_{\mathrm{e}}=2,056, p<.01\right]$. Finally, the subjects were significantly faster on withinblock transitions for both words $[F(1,30)=102.08$, $\left.M S_{\mathrm{e}}=455, p<.01\right]$ and color patches $[F(1,30)=$ $\left.114.66, M S_{\mathrm{e}}=1,977, p<.01\right]$.

In general, then, the data for the blocked condition indicate that the subjects were delayed when a new item had to be lexically encoded before the subject could respond (i.e., a between-block transition), but the delay was 


\begin{tabular}{|c|c|c|c|}
\hline \multirow[b]{2}{*}{ Display Condition } & \multicolumn{3}{|c|}{ Stimulus } \\
\hline & Word & Color & Means \\
\hline $\begin{array}{l}\text { Not saying "'square' } \\
\text { Between blocks } \\
\text { Within blocks }\end{array}$ & $\begin{array}{l}563 \\
521\end{array}$ & $\begin{array}{l}630 \\
515\end{array}$ & $\begin{array}{l}597 \\
518\end{array}$ \\
\hline Means & 541 & 573 & 557 \\
\hline $\begin{array}{l}\text { Saying "square" } \\
\text { Between blocks } \\
\text { Within blocks }\end{array}$ & $\begin{array}{l}521 \\
455\end{array}$ & $\begin{array}{l}592 \\
469\end{array}$ & $\begin{array}{l}556 \\
462\end{array}$ \\
\hline Means & 488 & 530 & 509 \\
\hline $\begin{array}{l}\text { Both conditions } \\
\text { Between blocks } \\
\text { Within blocks }\end{array}$ & $\begin{array}{l}542 \\
488\end{array}$ & $\begin{array}{l}611 \\
492\end{array}$ & $\begin{array}{l}577 \\
490\end{array}$ \\
\hline Means & 515 & 552 & 533 \\
\hline
\end{tabular}

less for color words than for color patches (the word advantage). In addition, within blocks for which no new lexical encoding would be needed, naming latencies were brief, and there was no difference between the naming of words and colors.

\section{Discussion}

As with Experiment 2, when the subjects had to come up with a new lexical encoding for every display (random condition), they were much faster at naming color words than at naming color patches (the word advantage). However, when the items were blocked into runs of displays that had the same name, the naming advantage for the words was radically reduced. In addition, the blocking effect occurred despite the fact that the perceiver had no way of knowing whether or not an upcoming item would be a repetition of the prior item until after it had been presented and encoded to the point of identification. For that reason, it seems clear that the two effects that occur when displays are blocked (i.e., the reduction in naming times and a reduction or elimination of the word advantage) have to be the result of some event that occurs after identification has been completed. Furthermore, the fact that there is no word advantage (and presumably no blocking effect) when the task involves a buttonpress rather than a lexical response (Fraisse, 1969) suggests that the critical postidentification event that is being influenced by blocking must involve some type of lexical processing.

Specifically, it was conjectured that, at any point in a series of displays, the lexical entry for the immediately preceding item remains activated and available. Given that that is the case, lexical activation can be bypassed when the display is a repetition of the prior item, because once the item has been identified, subjects can simply select the already activated entry for that item, and whether the display was a color word or color patch would be of no consequence. In the event that the new display did not match the prior item, lexical activation would be neces- sary. However, in the case of a word display, lexical activation would already have occurred as part of the identification process, and all that would be needed would be to select that entry and execute the response. For a color patch, on the other hand, lexical activation could occur only after the display had been identified as a new item, which would delay the response more than it would when the display was a word.

With respect to this final experiment, the critical data involve a comparison between the latencies for withinblock and between-block transitions, as well as a comparison between those latencies and the latencies for the random condition. The critical prediction was that if lexical activation is not necessary within blocks, and if such activation is a necessary condition for the word advantage, there should be no evidence of a word advantage within blocks, which the data indicated to be the case. Similarly, if lexical activation is necessary on betweenblock transitions, the usual word advantage should be obtained at those points, and the data are also consistent with that expectation.

The one result that is not completely consistent with the model is that the between-transition latency data are not identical to the latency data from the random condition (albeit they are very similar). A separate analysis comparing those conditions indicated only an unreliable 8 -msec difference between the conditions, but there was a significant condition $\times$ display-type interaction $[F(1,30)$ $=18.52, M S_{\mathrm{e}}=790, p<.01$ ], indicating a larger word advantage (or color-patch disadvantage) in the data from the random condition (110 $\mathrm{msec}$ vs. $72 \mathrm{msec}$ ). Although it was expected that those two effects should be more similar, part of the explanation could be reflected in the fact that a surprisingly large number of subjects spontaneously commented on the fact that the random color-patch list was especially difficult and fatiguing. Unfortunately, not only were the subjects significantly slower on the random color patches than on the color patches for the betweenblock condition, but, for the color-word displays, they were significantly faster on the random lists, and the fatigue explanation does not account for the latter effect.

In general, then, the comparison between the withinblock latencies and the between-block latencies offers striking support for the idea that the blocking effect stems from the subjects' ability to use an already active lexical encoding on within-block transitions. However, the fact that the between-block latencies do not look exactly like those for the random condition suggests that some other factor may be operating as well, and part of that might be the subjects' excessive fatigue on the random list of color patches.

Finally, half of the subjects were asked to say "square" when they saw the prefixation display. If the blocking effect occurred because the subjects were able to keep available a motor routine that conformed to the immediately preceding response, their saying "square" between displays should have replaced that routine with the one for "square," which should have eliminated the blocking ef- 
fect. However, that did not occur. The only effect of saying "square" was to speed up the response to the next display, which may have occurred because there was an optimal interstimulus interval between the warning event for the next display and the display for that condition. That is, for those subjects, the saying of "square" preceded the next display by $500 \mathrm{msec}$, whereas, for the other subjects, the only warning "event" was the onset of the fixation square, which preceded the next display by $750 \mathrm{msec}$.

With regard to the blocking effect, there was no influence at all stemming from the saying of "square," which strongly suggests that any carryover from one display to the next that is involved in the blocking effect probably is not in the form of a primed and active motor routine, but rather is in the form of a primed lexical entry that would need to be reexecuted (but not reactivated) in order to produce a response. One piece of data that might not be completely consistent with that idea is the fact that although within blocks the latencies for color words and color patches were the same, that equality was achieved in part by the fact that blocking slightly facilitated the naming of color words. That is, only after the lexical entry for a word has been activated can it be identified as being the same as the preceding item. However, if it has been activated for this display, what is the added value of also having a primed representation of that entry available from the last display? The only reasonable explanation is that there is some interaction between the persisting encoding of the prior item and the encoding of the new display as it is being encoded, which in some way speeds up the encoding process (e.g., the lexical entry might be selected early in processing on the basis of only a small amount of encoded visual information).

Overall, Experiment 3 does provide support for the idea that the persisting activation of the lexical representation of a just-seen display can be used for the naming of a new display. When the identification of the new display does not entail a lexical encoding (e.g., it is a picture rather than a word), a lexical recoding of the new item can be bypassed, and the perceiver can simply select that already active encoding.

\section{GENERAL DISCUSSION}

In conclusion, this study focused on Lund's (1927) report that the usual advantage in naming time for color words over color patches disappears if the words or patches are blocked so that all the items on a page have the same name. The goals of this study were to provide a clearer definition of that blocking effect (i.e., the elimination of the word-patch latency difference) and to ascertain whether an account of the effect could be made within the context of the generic model.

With regard to the definition of the effect, the data from these experiments indicate that it occurs even when the task demands that each stimulus event be fully encoded and identified, which seems to rule out simple explanations such as the bypassing of stimulus identification for blocked lists or the possibility of differential interference from neighboring stimuli in the two types of lists. The effect seems to emerge as a result of processing events that occur after identification has been completed.

In addition, the obvious influence of blocking is that it allows for the repeated use of some type of encoding, and is supported by the fact that, for blocked lists, the blocking effect occurred only on within-task transitions in which such repetition was possible. Furthermore, because the word advantage occurs only in tasks that require lexical access, it would appear that the encoding in question is either a lexical entry or a subsequent recoding of that information (e.g., a motor routine). However, the fact that subsequent vocal activity (e.g., saying "square") does not interfere with the blocking effect seems to point to the lexical entry as the critical encoding that is maintained by the repetition. That is, the execution of another motor routine should interfere with maintaining the critical routine in a primed state, but all the data from studies on semantic priming in lexical decision tasks indicate that it is quite possible to have more that one lexical entry primed.

Finally, these data can be handled quite well in the context of the generic model if we make the small additional assumption that activated lexical entries remain active and available for a short period of time after they have been used. Furthermore, with regard to that model, it seems quite clear that the difference in naming latencies between color words and color patches requires an assumption that words and patches have differential access to the lexicon, which is the core assumption of the generic model. The other alternative would be to assume a difference in the time needed to encode words and patches to the point of identification, but that is inconsistent with the fact that the latency difference was eliminated under blocked conditions that did require identification.

Overall, then, the blocking effect, as empirically defined by these experiments, can be readily understood in the context of the generic model. Furthermore, this enhanced definition of the effect adds credibility to the generic model because it seems to rule out, as part of the account of the word-naming advantage, any encoding event that occurs prior to the full identification of the display. In that context, the idea that words have a privileged access to the lexicon seems to be the most viable alternative.

\section{REFERENCES}

Brown, W. (1915). Practice in associating color-names with colors. Psychological Review, 22, 45-55.

CatTell, J. M. (1886). The time it takes to see and name objects. Mind, 11, 63-65.

CLARK, S. E. (1969). Retrieval of color information from the preperceptual storage system. Journal of Experimental Psychology, 82, 263-266.

Fraisse, P. (1969). Why is naming longer than reading? Acta Psychologica, 30, 96-103.

GaRReTt, H. E., \& LEMMON, V. W. (1924). An analysis of several well-known tests. Journal of Applied Psychology, 8, 424-438.

Glaser, W. R. (1992). Picture naming. Cognition, 42, 61-105. 
Gi.aser. W. R. \& Glaser, M. O. (1989). Context effects in Strooplike word and picture processing. Journal of Experimental Psycho/ogy: General, 118, 13-42

GOOL.KASIAN. P. (1981). Retinal location and its effects on the processing of target and distractor information. Journal of Experimental Psychologv: Human Perception \& Performance, 7, 1247-1257.

HaASE, S. J.. \& Theios, J. (1992). Conceptual categorization of lexical and pictorial stimuli. Paper presented at the meeting of the Midwestern Psychological Association, Chicago.

Hollingworth, H. L. (1915). Articulation and association. Journal of Educational Psychology, 6, 99-105.

Huttenlocher, J., \& Kubicek, L. F. (1983). The source of relatedness effects on naming latency. Journal of Experimental Psychology: Learning. Memon, \& Cognition, 9, 486-496.

JoHNSON, N. F. (1977). A pattern-unit model of word identification In D. LaBerge \& S. J. Samuels (Eds.), Basic processes in reading: Perception and comprehension (pp. 91-125). Hillsdale, NJ: Erlbaum. JOHNSON, N. F. (1981). Integration processes in word recognition. In O. Tzeng \& H. Singer (Eds.), Perception of print: Reading research in experimental psychology (pp. 29-64). Hillsdale, NJ: Erlbaum.

Johnson, N. F. (1991). Holistic models of word recognition. In R. Hoffman \& D. Palermo (Eds.), Cognitive psychology: The state of the ar (pp. 79-94). Hillsdale NJ: Erlbaum.

LA HEIJ, W. (1988). Components of Stroop-like interference in picture naming. Memory \& Cognition, 16, 400-410.

Ligon, E. M. (1932). A genetic study of color naming and word naming. American Journal of Psychology, 44, 103-110.

LUND, F. H. (1927). The role of practice in speed of association. Jour nal of Experimental Psychology, 10, 424-433.

LUPKER, S. J., \& KATZ, A. N. (1981). Input, decision, and response factors in picture-word interference. Joumal of Experimental Psychology: Human Learning \& Memory, 7, 269-282.

MaCLEOD, C. M. (1991). Half a century of research on the Stroop effect: An integrative review. Psychological Bulletin, 109, 163-203.

MCClain, L. (1983). Effects of response type and set size on Stroop color-word performance. Perceptual \& Motor Skills, 56, 735-743.

Nelson, D. L., ReEd, V. S., \& McEvor, C. L. (1977). Learning to order pictures and words: A model of sensory and semantic encoding. Journal of Experimental Psychology: Human Learning \& Memory, 3, 485-497.

Posner, M. I., Boies, S. J., Eichelman, W. H., \& Taylor, R. L. (1969). Retention of visual and name codes of single letters. Journal of Experimental Psychology Monographs, 79 (1, Pt. 2), 1-16.

Potter, M. C., \& Faulconer, B. A. (1975). Time to understand pictures and words. Nature, 253, 437-438.

RABBITT, P., \& RoDGERS, B. (1977). What does a man do after he makes an error? An analysis of response programming. Quarterly Journal of Experimental Psychology, 29, 727-743.

RAYNER, K. (1975). The perceptual span and peripheral cues in reading. Cognitive Psychology, 7, 65-81.

Smith, M. C., \& Magee, L. E. (1980). Tracing the time course of picture-word processing. Journal of Experimental Psychology: General, 109, 373-392.

SNODGRass, J. G. (1984). Concepts and their surface representations. Journal of Verbal Learning \& Verbal Behavior, 23, 120-139.

SNodgrass, J. G., \& MCCullough, B. (1986). The role of visual similarity in picture recognition. Journal of Experimental Psychology. Learning, Memory, \& Cognition, 12, 147-154.

SPERLING, G. J. W. (1960). The information available in brief visual presentation. Psychological Monographs, 74 (Whole No. 498).

Stroop, J. R. (1935a). The basis of Ligon's theory. American Journal of Psychology, 47, 499-504.

STROOP, J. R. (1935b). Studies of interference in serial verbal reactions. Journal of Experimental Psychology, 18, 643-662.

Theios, J., \& AMrhein, P. C. (1989). Theoretical analysis of the cognitive processing of lexical and pictorial stimuli: Reading, naming, and visual and conceptual comparisons. Psychological Review, 96, 5-24.

Woodworth, R. S., \& Wells, F. L. (1911). Association tests. Psychological Monographs, 13 (Whole No. 57).

(Manuscript received September 23, 1992; revision accepted for publication July 19, 1993.) 